\title{
Evaluating noninvasive ventilation using a monitoring system coupled to a ventilator: a bench-to-bedside study
}

\author{
C. Rabec*, M. Georges*, N.K. Kabeya*,", N. Baudouin*, F. Massin*, \\ O. Reybet-Degat* and P. Camus*
}

ABSTRACT: Empirically determined noninvasive ventilation (NIV) settings may not achieve optimal ventilatory support. Some ventilators include monitoring modules to assess ventilatory quality. We conducted a bench-to-bedside study to assess the ventilatory quality of the VPAP ${ }^{\mathrm{TM}}{ }_{\text {III- }}$ ResLink $^{\mathrm{TM}}$ (ResMed, North Ryde, Australia).

We tested the accuracy of minute ventilation (MV) and leak calculations given by VPAP ${ }^{\mathrm{TM}}{ }_{\text {III- }}$ ResLink $^{\mathrm{TM}}$ compared to those measured by a bench model at varied leak levels and ventilator settings. We systematically assessed NIV efficacy using this system from 2003 to 2006 . Ventilation was considered inadequate if leak $\left(>24 \mathrm{~L} \cdot \mathrm{min}^{-1}\right)$, continuous desaturation $(>30 \%$ of the trace) or desaturation dips (>3\%) were present.

On the bench test, both methods were highly correlated $(r=0.947, p>0.0001$ and $r=0.959$, $\mathbf{p}<0.0001$ for leak and MV, respectively). We performed 222 assessments in 169 patients (aged $66.42 \pm 16$ yrs, 100 males). Abnormalities were detected on 147 (66\%) out of 222 occasions. Leak was the most common abnormality (34.2\%) followed by desaturation dips (23.8\%). The most effective therapeutic solutions were a chin strap if leak was detected $(61.2 \%)$ and expiratory positive airway pressure increase for desaturation dips $(59.5 \%)$. In $15.7 \%$ of cases, when abnormalities persisted, a polygraphy was performed.

The systematic use of this device enables NIV to be optimised, limiting the indication of sleep studies to complex cases.

KEYWORDS: Bench testing, bi-level positive airway pressure, clinical evaluation, monitoring, noninvasive ventilation, respiratory failure

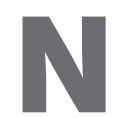
oninvasive ventilation (NIV) has been demonstrated to be effective treatment in respiratory failure. In some cases, however, the clinical results may be less than expected, despite using the correct technique. When NIV is initiated, the ventilator settings are determined empirically based on clinical evaluation of underlying disease, patient tolerance when awake, and diurnal blood gas variations [1]. However, NIV is predominantly applied at night [2], when profound ventilatory changes may occur, particularly in patients with respiratory failure [3]. Such changes include modifications of ventilatory control, upper airway patency and respiratory muscle recruitment. Consequently, modulating NIV settings during the day and underestimating these physiological differences may lead to suboptimal patientventilator interaction that reduces NIV efficacy.
Moreover, NIV uses a non-hermetic technique, which poses the possible risk of leak. Leakage may be absent or minimal when the patient is awake and may worsen during sleep as a result of the loss of voluntary control and decreased muscle tone. Thus, NIV settings chosen empirically on daytime evaluation may not predict optimal nocturnal ventilatory support. Consequently, NIV effectiveness may be more correctly assessed by sleep studies than through daytime assessment [1]. Ideally this requires complete polysomnography (PSG) or ventilatory polygraphy (PG) at the time of initiation to NIV. However, it is not technically feasible to perform repeated long-term assessment by PG/PSG in these patients.

Recently, NIV has been provided by portable ventilators capable of meeting high ventilatory demands [4]. Some of these ventilators include
AFFILIATIONS

* Service de Pneumologie et Réanimation Respiratoire, Centre Hospitalier et Universitaire de Dijon, and

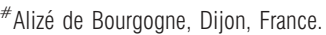

CORRESPONDENCE

C. Rabec

Service de Pneumologie et

Réanimation Respiratoire

Centre Hospitalier et Universitaire de Dijon

2 Bd Maréchal de Lattre de Tassigny 21079 Dijon

France

E-mail: claudio.rabec@chu-dijon.fr

Received:

Nov 102008

Accepted after revision:

March 162009

First published online:

March 262009 
monitoring modules that can assess various ventilatory parameters, storing the data in memory for subsequent analysis. Such technology and its clinical usefulness merits critical analysis.

We wanted to assess one of these systems, which consisted of a ventilator $\left(\mathrm{VPAP}^{\mathrm{TM}} \mathrm{III}\right)$ and its monitoring module (ResLink $\left.{ }^{\mathrm{TM}}\right)$. We assessed the accuracy of the parameters measured by this device in a bench model. In addition, we investigated the results of using the system by systematically assessing the efficacy of the NIV in different clinical situations.

\section{MATERIALS AND METHODS}

The VPAP ${ }^{\mathrm{TM}}$ III-ResLink ${ }^{\mathrm{TM}}$ (ResMed, North Ryde, Australia) is a bi-level ventilator that includes a monitoring system which provides trend data on minute ventilation (MV) (defined as estimated MV received by the patient after the removal of leak), respiratory rate, air leaks (above "intentional" ones), arterial oxygen saturation measured by pulse oximetry $\left(\mathrm{Sp}, \mathrm{O}_{2}\right)$ and heart rate; all of which are analysed by the software package AutoScan $5.7^{\mathrm{TM}}$ (ResMed). The monitoring module, ResLink $^{\mathrm{TM}}$, obtains the information from signals received at the mask and only requires an additional connection to a pulse oximeter (included). The oximeter has a sampling frequency of $1 \mathrm{~Hz}$ and an average of the $\mathrm{Sp}, \mathrm{O}_{2}$ value is made over the last four beats. For the oxygen desaturation index, the averaging window is $5 \mathrm{~s}$ in duration. The data can be stored on a SmartMedia card (Sandisk, Milpita, CA, USA) and transferred to a computer for simultaneous onscreen viewing.

\section{Bench study}

In an artificial lung model, we tested the accuracy of the MV and leak estimation calculated by ResLink ${ }^{\mathrm{TM}}$, and compared these results with a reference system.

The artificial lung is composed of two 40-L Nalgene ${ }^{\circledR}$ translucent polycarbonate canisters (Bioblock Scientific, Illkirch, France). Details on the lung prototype can be seen in figure 1 of the supplementary data. The ventilator and monitoring module were connected to the lung model by a $60-\mathrm{cm}$ long section of tubing. We included the following in the circuit. 1) A variable-opening valve providing a variable leak of $0-180 \mathrm{~L} \cdot \mathrm{min}^{-1}$ joined by a Y-connection to a first pneumotachograph (RT200 ${ }^{\mathrm{TM}}$; Timeter Instruments, St Louis, MO, USA). 2) A second flow-measurement system located downstream and capable of measuring the actual MV. A ventilatortesting device (Ventest ${ }^{\mathrm{TM}}$; Soderel, Heillecourt, France) was used to measure MV and calculate compliance and resistance. To simulate physiological ventilation conditions, a leak device corresponding to the intentional leak of the mask stated in the system was included ("calibrated leak"). With the VPAP ${ }^{\mathrm{TM}} \mathrm{III}-$ ResLink $^{\mathrm{TM}}$, the type of mask and circuit length could be registered, which enables the device to "know" the value of the intentional leak and subtract it from the estimated leak. We used an intentional leak corresponding to a standard mask $\left(25 \mathrm{~L} \cdot \mathrm{min}^{-1}\right.$ at $10 \mathrm{cmH}_{2} \mathrm{O}$ ), and the length of the circuit was $3 \mathrm{~m}$. These were the values registered in the system. The protocol consisted of a total of 48 recordings of 10 min each, at leak levels of $0,18,24$ and $30 \mathrm{~L} \cdot \mathrm{min}^{-1}$ (when the apparatus was tested in a bi-level mode, this value corresponded to the maximum leak during the inspiratory phase) at different ventilatory settings (fig. 1), resulting in varying compliance and resistance as follows. 1) Compliance: $50 \mathrm{~mL} \cdot \mathrm{cmH}_{2} \mathrm{O}^{-1}$, resistance: $4 \mathrm{cmH}_{2} \mathrm{O} \cdot \mathrm{L}^{-1} \cdot \mathrm{s}^{-1}$ (physiological); 2) compliance: $50 \mathrm{~mL} \cdot \mathrm{cmH}_{2} \mathrm{O}^{-1}$, resistance: $15 \mathrm{cmH} \mathrm{O}_{2} \cdot \mathrm{L}^{-1} \cdot \mathrm{s}^{-1}$ (increased resistance); and 3) compliance: $25 \mathrm{~mL} \cdot \mathrm{cmH}_{2} \mathrm{O}^{-1}$, resistance: $4 \mathrm{cmH}_{2} \mathrm{O} \cdot \mathrm{L}^{-1} \cdot \mathrm{s}^{-1}$ (reduced compliance). ResLink ${ }^{\mathrm{TM}}$ estimates averaged values while the pneumotachograph measures instant flow in inspiration and expiration. Therefore, we expressed a mean leak for pneumotachograph measures. This was the maximum instantaneous leak in inspiration and expiration weighted to the duration of inspiratory and expiratory phases. The device was set in the "T-mode" with an inspiration/expiration ratio of 1:2.

Data provided by the VPAP ${ }^{\mathrm{TM}} \mathrm{III}-\operatorname{ResLink}^{\mathrm{TM}}$ were then recorded on a SmartCard, which was then transferred to a computer and visualised via the AutoScan $5.7^{\mathrm{TM}}$ program in order to compare them with the reference values.

\section{Clinical study}

We included patients recruited between 2003 and 2006 treated with NIV using VPAP ${ }^{\mathrm{TM}} \mathrm{III}$, either in the acute setting (acute respiratory failure (ARF) group) or electively, in patients for whom home MV was indicated (chronic respiratory failure (CRF) group).

The efficacy of ventilation was monitored using ResLink ${ }^{\mathrm{TM}}$ under ventilation conditions (parameters and interfaces) present at the time of assessment. In patients discharged home with NIV, another trace was performed 4-6 months later to confirm NIV efficacy (long-term mechanical ventilation (LTMV) group) under the parameters used at home. The ResLink $^{\mathrm{TM}}$ criteria used to define ventilation as ineffective were as follows: 1) leakage $>24 \mathrm{~L} \cdot \mathrm{min}^{-1}$ for $>20 \%$ of the trace duration; 2 ) continuous desaturation $(>30 \%$ of the trace with $\mathrm{Sp}_{\mathrm{p}} \mathrm{O}_{2}<90 \%$ ), whether or not accompanied by a simultaneous reduction of $\mathrm{MV}(>10 \%$ of reduction of MV compared to baseline) estimated by the $\operatorname{ResLink}^{\mathrm{TM}}$, in the absence of significant leak; and 3) cumulated desaturation dips ( $>3 \%)$ for $>10 \%$ of the trace duration. If these criteria were not met then the ventilation was considered effective. The data were analysed using the AutoScan $5.7^{\mathrm{TM}}$ software package. If one of these abnormality criteria were detected, one or more conditions were modified to optimise ventilation and another recording was performed. This procedure was repeated until the best possible results were obtained. When the trace could not be corrected despite these changes, we performed PG/PSG under ventilation. This PG/PSG included, at least, pneumotachograph-based airflow, mask pressure, thoracoabdominal movements and $\mathrm{Sp}, \mathrm{O}_{2}$ recordings. Typical $\operatorname{Reslink}^{\mathrm{TM}}$ traces of the various abnormalities are shown in figure 2. Arterial blood gases (ABG) during spontaneous ventilation were measured under the conditions of oxygenation at the time of assessment. In the ARF and CRF patient groups, ABG were sampled before the start of ventilation and in the LTMV group during the first hour in the morning after the patient was disconnected from the ventilator.

\section{Statistical analysis}

Values are shown as mean \pm SD. The values for MV and leak obtained by the two methods in the bench study were correlated by linear regression using Pearson's correlation coefficient. We also calculated the bias (where $\mathrm{d}$ is the mean 


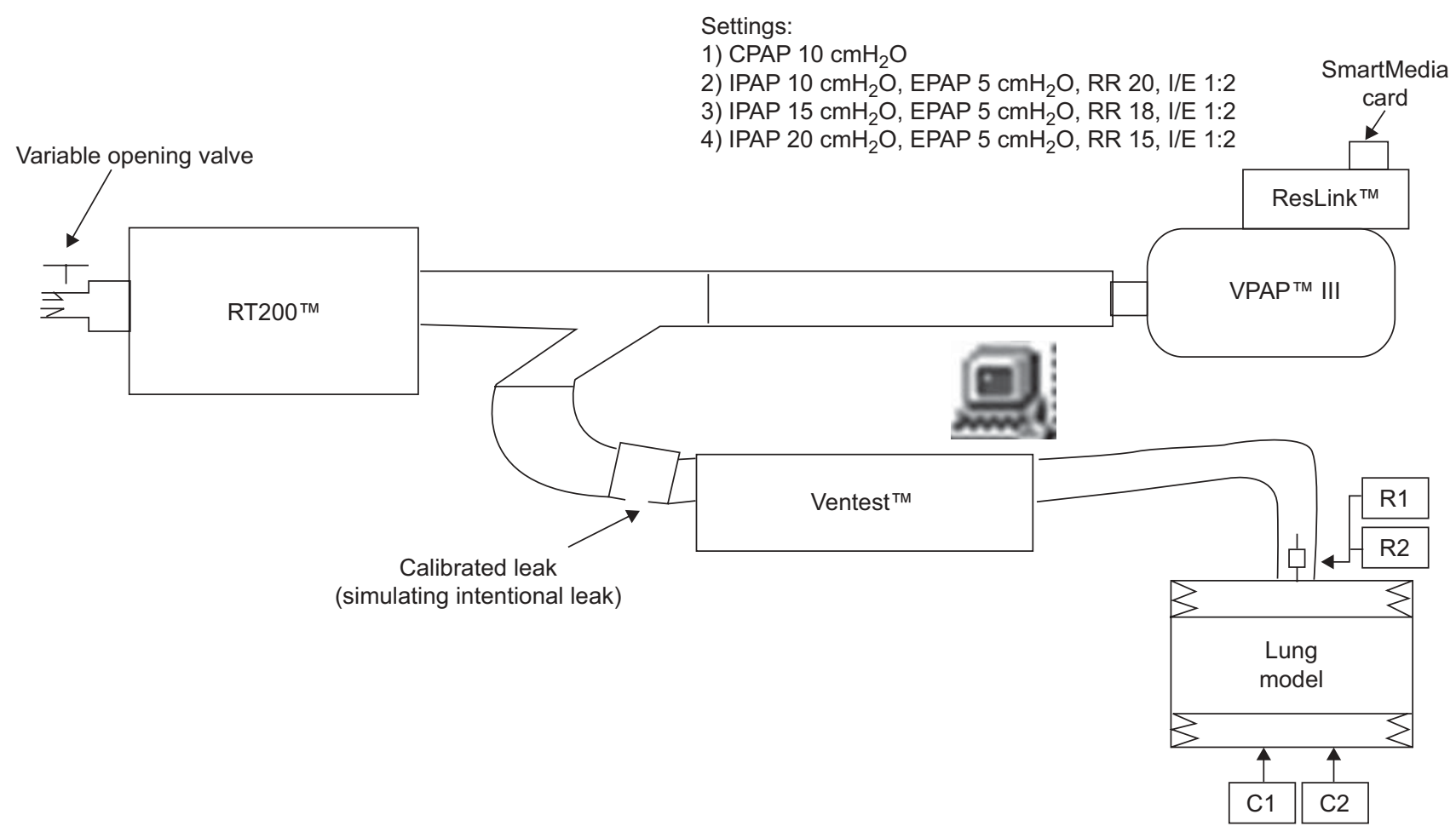

FIGURE 1. Schematic representation of the bench model. The protocol consisted of a total of 48 recordings of 10 min each, at leak levels of $0,18,24$ and $30 \mathrm{~L} \cdot \mathrm{min}^{-1}$. The different ventilatory settings are shown. The device was set in the "T-mode" with an inspiration/expiration (I/E) ratio of 1:2. CPAP: continuous positive airway pressure; IPAP: inspiratory positive airway pressure; EPAP: expiratory positive airway pressure; RR: respiratory rate; R: resistance; C: compliance. RT200 ${ }^{\mathrm{TM}}$ : Timeter Instruments, St Louis, MO, USA. Ventest ${ }^{\mathrm{TM}}$ : Soderel, Heillecourt, France. VPAP ${ }^{\mathrm{TM}}{ }_{\text {III-ResLink }}{ }^{\mathrm{TM}}$ : ResMed, North Ryde, Australia.

difference between reference bench measures and the ResLink $^{\mathrm{TM}}$ estimated values) and the limits of agreement between the parameters as described by BLAND and ALTMAN [5]. For the clinical study, data were compared using the unpaired t-test and Mann-Whitney U-test. Differences between the groups were assessed using ANOVA. A Chisquared analysis was performed to study categorical data. A p-value of 0.05 was considered as significant.

\section{RESULTS}

\section{Bench study}

The correlations between values obtained by pneumotachograph and those estimated by the VPAP ${ }^{\mathrm{TM}}$ III-ResLink ${ }^{\mathrm{TM}}$ are shown in figure $3 a$ and $b$. Both sets of measurement were highly correlated (leak: $r=0.947$ and $p>0.0001 ; M V: r=0.959$ and $\mathrm{p}<0.0001$ ), as was the correlation for data subgroups (for both MV and leak) but the correlation of leak was not as good at low leak levels (at $18 \mathrm{~L} \cdot \mathrm{min}^{-1}: \mathrm{r}=0.853$ and $\mathrm{p}<0.001$ ). Figure $3 c$ and $d$ shows Bland-Altman plots of the agreement between pneumotachograph-measured leak and MV and ResLink $^{\mathrm{TM}}$ values. For all observed values of leak and MV, the mean observed bias was $0.736 \pm 1.68$ and $0.077 \pm 0.97 \mathrm{~L} \cdot \mathrm{min}^{-1}$, respectively. The limits of agreement between both techniques were -4.04 and $2.57 \mathrm{~L} \cdot \mathrm{min}^{-1}$ for leak and -1.82 and $1.97 \mathrm{~L} \cdot \mathrm{min}^{-1}$ for MV. Again the agreement was less for low leak values $\left(<22 \mathrm{~L} \cdot \mathrm{min}^{-1}\right)$.

\section{Bedside study}

NIV efficacy was assessed for 222 different hospital admissions in 169 patients (aged 66.42 \pm 16 yrs, 100 males). During each admission one or more traces were performed. The total number of recordings performed was 542. Amongst them, 500 traces were useful for analysis $\left(2.25 \pm 1.45\right.$ traces admission $\left.^{-1}\right)$ and $42(8.4 \%)$ traces were not suitable for analysis because of technical problems. $69(31.08 \%)$ assessments were performed in patients in the ARF group (180 valid traces, $2.6 \pm 1.72$ traces $\cdot$ patient $\left.^{-1}\right), 53(23.8 \%)$ in the CRF group (147 valid traces, $2.77 \pm 1.75$ traces $\cdot$ patient $\left.{ }^{-1}\right)$ and $100(44.59 \%)$ in those from the LTMV group (173 valid traces, $1.73 \pm 0.95$ traces $\cdot$ patient $^{-1}$ ). Oxygen therapy was added on 112 occasions to ensure diurnal arterial oxygen tension $\left(\mathrm{Pa}_{\mathrm{a}} \mathrm{O}_{2}\right)>60 \mathrm{mmHg}$ (69 out of 69 in ARF, 20 out of 53 in CRF and 23 out of 100 in LTMV). The difference between the numbers of traces per admission was significant between ARF and LTMV and between CRF and LTMV, but not between ARF and CRF (table 1). 50 patients were assessed on two different occasions and two patients on three occasions. A nasal mask (NM) was used on $167(75.2 \%)$ occasions and a facial mask (FM) on $55(24.8 \%)$. Patients in the ARF group are significantly older than the patients in the other groups.

Table 2 illustrates the classification of patients according to the categories defined in the Eurovent survey [6]. Patient characteristics, ventilatory parameters and ABG values are shown in table 1 . There were no significant differences in ventilatory settings for the three groups. However, differences in the types of interfaces used were observed, with a gradual increase in the use of NMs compared to FMs as patients progressed from an acute to a more stable situation (nasal mask $\mathrm{ARF}<\mathrm{CRF}<\mathrm{LTMV})(\mathrm{p}<0.01)$. 

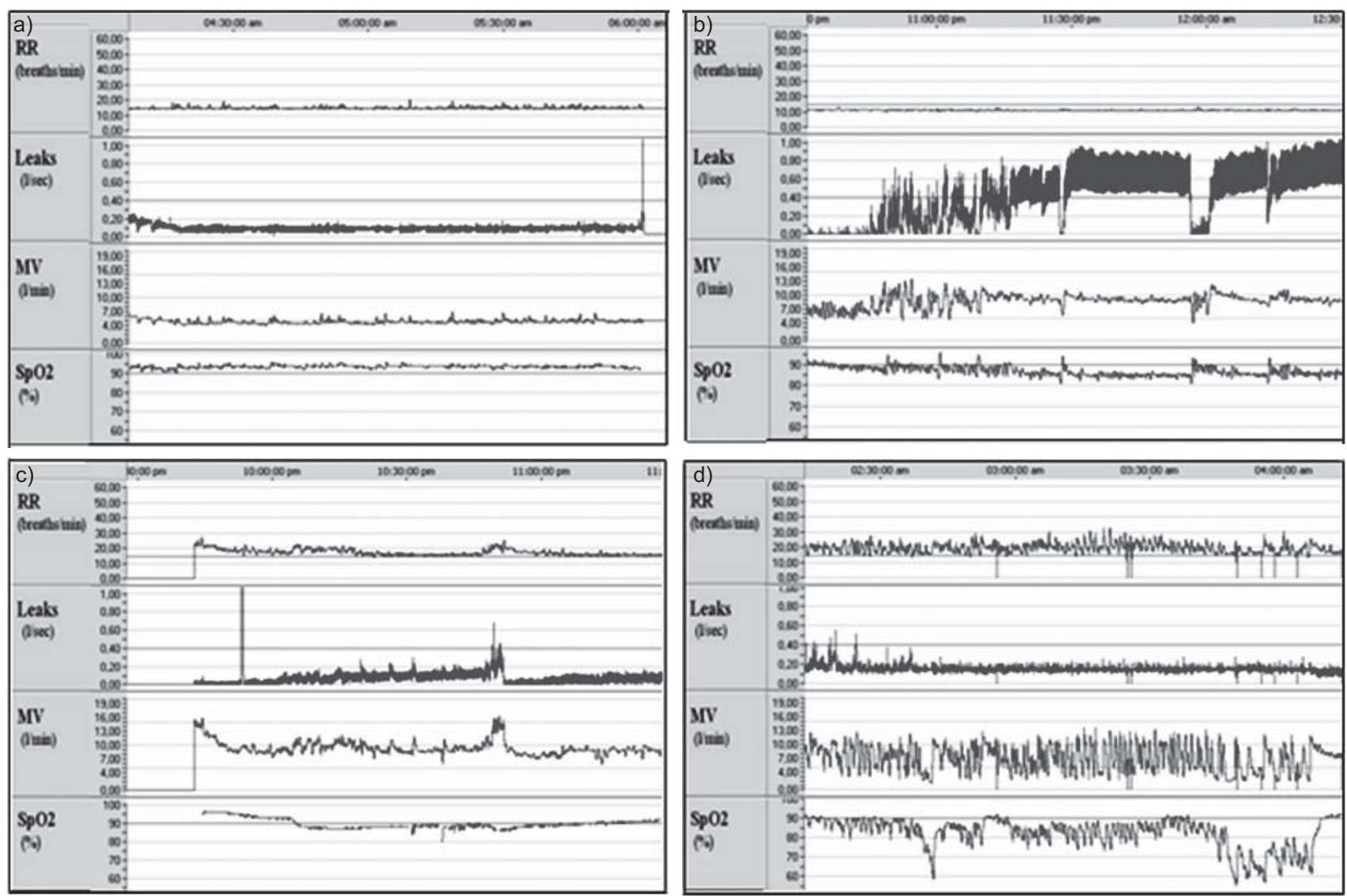

FIGURE 2. VPAP ${ }^{T M} I I-$ ResLink ${ }^{T M}$ System (ResMed, North Ryde, Australia) characteristic traces ( $2 \mathrm{~h}$ per page). a) Normal trace; b) trace showing leaks $>0.40 \mathrm{~L} \cdot \mathrm{s}^{-1}$ followed by drop in arterial oxygen saturation measured by pulse oximetry $\left(\mathrm{Sp}, \mathrm{O}_{2}\right) ; \mathrm{C}$ ) trace showing continuous desaturation accompanied by a drop in minute ventilation (MV) as estimated by the ventilator (without leaks); d) trace showing desaturation dips (see oscillations in respiratory rate (RR) and MV as a reflection of desaturation dips).

\section{Results of the ResLink monitoring traces}

Abnormalities were detected on $147(66 \%)$ of the 222 occasions. In the group as a whole, $129(76.3 \%)$ out of 169 patients presented with abnormalities in some of the assessments, most commonly in the ARF (53 (76.8\%) out of 69 occasions) and CRF (41 (77.3\%) out of 53 occasions) groups compared to the LTMV group (53 (53.0\%) out of 100 occasions). The differences in the number of abnormalities were significant between ARF and LTMV and between CRF and LTMV $(\mathrm{p}<0.05)$ but not between ARF and CRF. These abnormalities were significantly more common when using a NM in ARF $(p<0.02)$ but not in CRF or LTMV. The proportion of patients with suboptimal ventilation was similar, independent of the disease category or ventilatory parameters. There were no differences regarding subjective perception of quality of sleep as evaluated by a categorical scale (poor-fair-good) between patients with and without abnormalities.

Leak was the most common abnormality in the overall population (76 (34.2\%) occasions) and also in the ARF (30 (43.4\%) occasions) and CRF (21 (39.6\%) occasions) groups. In the LTMV group, leak was less common (25 (25\%) occasions), and the number of cases was significantly smaller compared with ARF $(p<0.02)$ but not with CRF. Leak seems to be unrelated to inspiratory positive airway pressure (IPAP) levels and was significantly more common in the overall population when a NM was used $(p<0.01)$. The second most common abnormality was $3 \%$ desaturation dips that were observed on $53(23.8 \%)$ occasions with no significant differences between the three groups. A significantly greater prevalence of desaturation dips was observed with FM than NM $(p<0.04)$, but only the ARF group contributed to this difference. Finally, episodes of continuous desaturation were observed on 18 $(8.1 \%)$ occasions with no significant differences between the three groups, and a similar prevalence of these events with both interfaces. On 10 occasions $(4.5 \%$ of the total $)$ the desaturation episodes were accompanied by a significant reduction in MV.

Figures 4, 5 and 6 illustrate the results of the recordings, categorised by clinical situation, and subsequent therapeutic modifications. The results classified by type of abnormality and interface can be seen in table 3 .

\section{Comparison between patients with normal and abnormal traces}

Relationship between $A B G$ and monitoring results

Table 4 shows a comparison of ABG between patients with normal and abnormal ResLink ${ }^{\mathrm{TM}}$ traces. These were sampled prior to the start of the ventilation in ARF and CRF and on spontaneous ventilation after disconnecting the ventilator in LTMV. When ABG values in LTMV patients with abnormal 

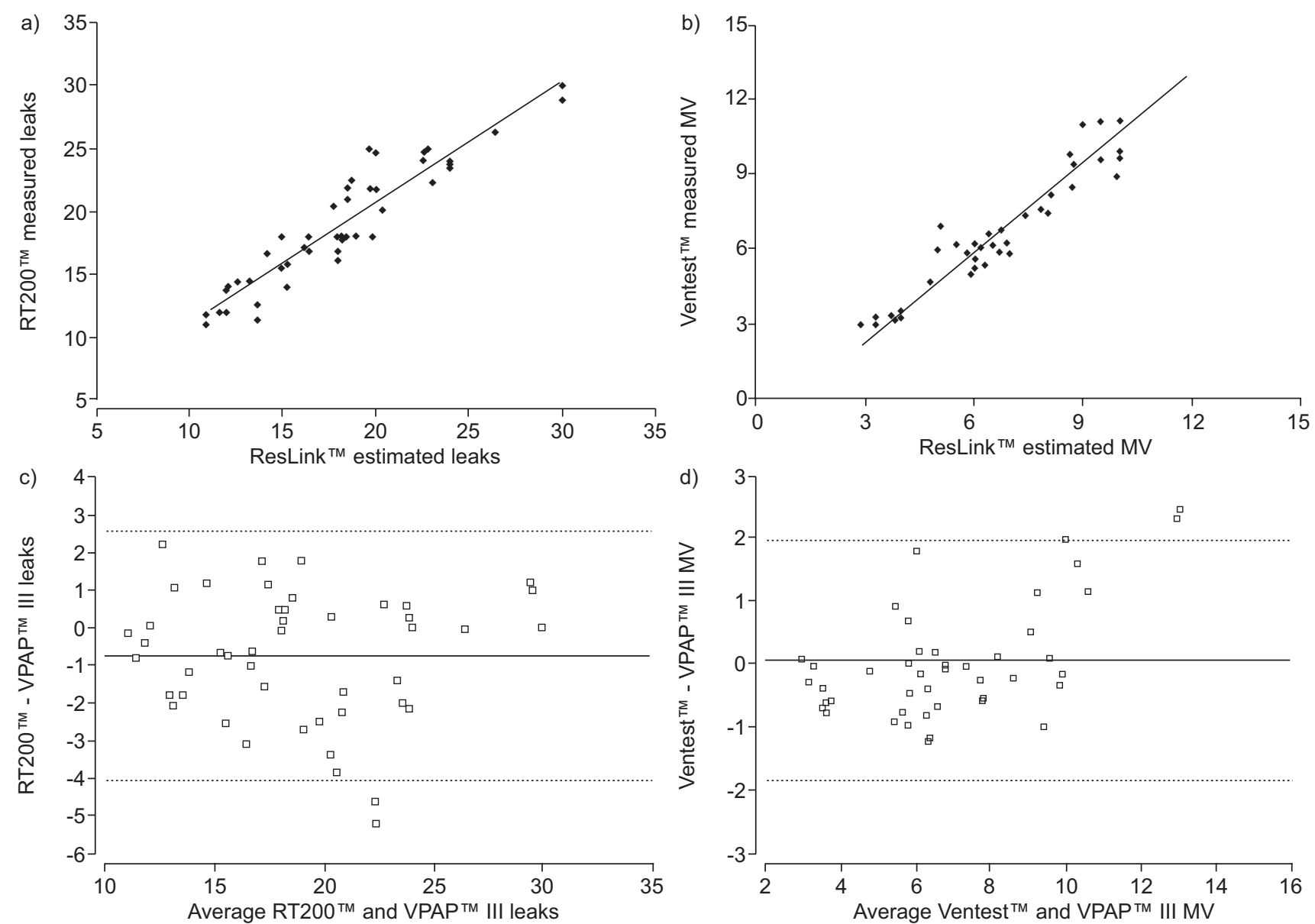

FIGURE 3. Pearson correlation between values of measured a) leaks (RT200 ${ }^{\mathrm{TM}}$; Timeter Instruments, St Louis, MO, USA) and b) minute ventilation (MV) (Ventest ${ }^{\mathrm{TM}}$

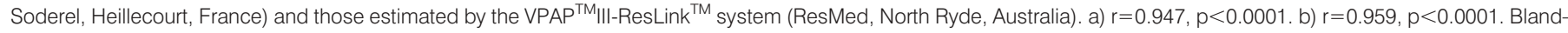
Altman plots for the differences against mean for $\mathrm{c})$ leaks $(n=48)$ and d) MV $(n=45)$. — : mean; ......: \pm 1.96 sD from the mean.

traces were compared according to the type of ResLink ${ }^{\mathrm{TM}}$ abnormality, we did not find significant differences between the three groups of abnormalities as regards arterial carbon dioxide tension $\left(\mathrm{Pa}_{\mathrm{a}} \mathrm{CO}_{2}\right)$ and $\mathrm{pH} . \mathrm{Pa}, \mathrm{O}_{2}$ was significantly worse in patients with an abnormal trace, with continuous desaturation being associated with the lowest $\mathrm{Pa}_{\mathrm{a}} \mathrm{O}_{2}$, followed by the desaturation dips, and the group with leak having the least impact.

\section{Additional data concerning the LTMV group} Comparative mean compliance

There were no differences in terms of daily duration of ventilator use between patients with normal and abnormal ResLink ${ }^{\mathrm{TM}}$ traces $\left(7.92 \pm 2.2\right.$ and $7.90 \pm 2.0 \mathrm{~h} \cdot \mathrm{day}^{-1}$, respectively).

\section{Modifications in ventilation as a result of the monitoring}

Figures 4, 5 and 6 and table 3 illustrate the modifications made as a result of monitoring, classified by situation and interface, respectively. If leaks were detected, the most common approach was to add a chin strap (49 (64\%) out of 76 patients ventilated with a NM), which was effective in $30(61.2 \%)$ patients. The efficacy of this was similar in the three clinical situations. In the case of desaturation dips, the most common approach used was to increase expiratory positive airway pressure (EPAP; 42 (79.2\%) out of 53 occasions), which was effective in $25(59.5 \%)$ out of 42 cases. For continuous desaturation, the effective modifications were to increase IPAP $(10(55.55 \%)$ out of 18 cases) or add oxygen (eight (44.4\%) out of 18 cases). Only one modification was required in 81 cases, two in 33 patients and three or more in 30 patients. In $35(15.7 \%)$ cases, it was judged necessary to perform PG/PSG under ventilation (see online supplement). The need for PG was significantly more common in ARF (19 (27.5\%) out of 69$)$ than in LTMV (seven $(7 \%)$ out of 100$) \quad(p<0.01)$. The abnormality that most frequently indicated a PG/PSG was desaturation dips (21 (60\%) out of 35 cases).

\section{DISCUSSION}

NIV is a non-hermetic system compared to invasive ventilation, and the ventilator-lung assembly cannot be considered as a single-compartment model because of the presence of variable resistance in the upper airway (UA) [7]. Therefore, increasing the volume or the delivered inspiratory pressure does not necessarily result in increased effective ventilation reaching the lungs [8-10]. It is therefore essential to assess the clinical efficacy of NIV in all patients and this evaluation should include at least a clinical assessment and measurement of ABG and nocturnal $\mathrm{Sp}_{\mathrm{p}} \mathrm{O}_{2}$ under NIV $[11,12]$. However, this 
TABLE 1 Ventilation settings, arterial blood gases and number of studies performed, classified by clinical situation

At the start of long-term ventilation: $\mathrm{CRF}$

\section{Age yrs}

BMI $\mathbf{k g} \cdot \mathrm{cm}^{-2}$

FEV $1 \mathrm{~L} \cdot \mathrm{s}^{-1}$

FEV $1 \%$ pred

FVC L

FVC \% pred

Mask type nasal/facial ${ }^{\#}$

IPAP $\mathrm{CmH}_{2} \mathrm{O}$

EPAP $\mathrm{cmH}_{2} \mathrm{O}$

Backup respiratory rate

$\mathrm{Pa}, \mathrm{O}_{2} \mathrm{mmHg}^{\mathrm{I}}++$

$\mathrm{Pa}, \mathrm{CO}_{2} \mathrm{mmHg}^{\mathrm{T}}$,

$\mathrm{pH}^{\mathrm{t},+}$

Number of traces per clinical situation

Number of polygraphys/clinical situation

$$
\begin{gathered}
69.5 \pm 16 \\
29.2 \pm 9 \\
0.97 \pm 0.68^{\S} \\
40.9 \pm 19.7 \\
1.56 \pm 0.77^{\S} \\
51.4 \pm 17 \\
36 / 33 \\
16.6 \pm 1.9 \\
5.2 \pm 1.8 \\
14.5 \pm 1.10 \\
61.3 \pm 12.8 \\
68.6 \pm 13.8 \\
7.32 \pm 6.0 \\
2.6 \pm 1.7 \\
19 / 69
\end{gathered}
$$

$$
\begin{gathered}
60,8 \pm 18^{*} \\
29.7 \pm 10 \\
1.15 \pm 0.6^{*} \\
45.3 \pm 17 \\
1.51 \pm 0.74 \\
49.3 \pm 20 \\
41 / 12^{*} \\
16.6 \pm 2.0 \\
5.4 \pm 2.2 \\
14.0 \pm 1.5 \\
65.3 \pm 11.6 \\
55.9 \pm 9.3^{*} \\
7.37 \pm 3.5^{*} \\
2.7 \pm 1.5 \\
9 / 53^{\# \#}
\end{gathered}
$$

At steady state: LTMV p-value

At steady state: LTMV p-value

Data are presented as mean \pm SD or $\mathrm{n} / \mathrm{n}$. ARF: acute respiratory failure; CRF: chronic respiratory failure; LTMV: long-term mechanical ventilation; BMI: body mass index; FEV1: forced expiratory volume in one second; \% pred: \% predicted; FVC: forced vital capacity; IPAP: inspiratory positive airway pressure; EPAP: expiratory positive airway pressure; $\mathrm{Pa}, \mathrm{O}_{2} ;$ arterial oxygen tension; $\mathrm{Pa}_{2} \mathrm{CO}_{2}$ : arterial carbon dioxide tension; NS: nonsignificant. ${ }^{*}$ : as the device makes it possible to set parameters for the type of mask used in order to abstract the amount of intentional leak, preference was given to the types of masks that could be preset in the device. If this was not possible, the mask used was that with the closest intentional leak. Accordingly, we previously measured the intentional leak for each mask in our laboratory; " : breathing room air or under supplemental oxygen therapy; ${ }^{+}$: prior to the start of the ventilation in ARF and during the first hour in the morning after the patient was disconnected from the ventilator in CRF and LTMV; ${ }^{\S}$ : data lacking in 10 patients of this group; $f: p<0.05$ compared to CRF using the Mann-Whitney rank sum test; ${ }^{\# \#: ~} p<0.056$ compared with ARF. ${ }^{*}: p<0.05$ compared to ARF.

may not be sufficient. For example, while an abnormal $S \mathrm{p}, \mathrm{O}_{2}$ reflects, on the whole, inoptimal ventilation, it does not determine the underlying mechanism [11, 12]. Moreover, even a "normal" $\mathrm{Sp}, \mathrm{O}_{2}$ does not rule out the possibility of nocturnal

\begin{tabular}{lc} 
TABLE 2 & $\begin{array}{c}\text { Classification of disease categories for patients } \\
\text { included in the study according to the Eurovent } \\
\text { survey [6] }\end{array}$ \\
Aetiological group & Subjects \\
\hline Lung and airways & $85(50.3)$ \\
COPD & 45 \\
Overlap syndrome & 35 \\
Cystic fibrosis & 4 \\
Others & 1 \\
Chest wall abnormalities & $54(32)$ \\
Obesity hypoventilation syndrome & 32 \\
Tuberculosis sequelae & 12 \\
Kyphoscoliosis & 10 \\
Neuromuscular diseases & $30(17.7)$ \\
Myopathy & 12 \\
Amyotrophic lateral sclerosis & 10 \\
Phrenic nerve paralysis & 5 \\
Others & 3 \\
\hline
\end{tabular}

Data are presented as $\mathrm{n}(\%)$ or $\mathrm{n}$. COPD: chronic obstructive pulmonary disease. hypoventilation, particularly if the patient is receiving supplemental oxygen [12-14]. Consequently, more specific monitoring is necessary. Some authors have suggested that all patients receiving NIV should be tested by PSG to verify its efficacy [1, $15,16]$ but, in reality, this practice is infrequent [3]. This is on account of the workload and the lack of available PSG devices, but also due to the difficulty in interpreting the ventilatory signals under NIV, which needs a high level of experience. In addition, in order to understand patient-ventilator interactions, the PSG must include at least one signal to detect inspiratory activity (oesophageal pressure or diaphragmatic electromyography) and monitoring of this type may itself change sleep quality. Therefore, "interpreting polysomnography under NIV is a very difficult task" [17]. Finally, it is impossible to perform polysomnography after every therapeutic modification. Thus, the systematic use of PSG would be very difficult. In addition there has been an exponential growth in the number of patients receiving NIV in recent years and, therefore, performing polysomnography on all ventilated patients becomes increasingly difficult.

Some portable ventilators include technologies that allow monitoring of ventilatory parameters. In this study we assessed the efficacy of NIV using the VPAP ${ }^{\mathrm{TM}}$ III-ResLink ${ }^{\mathrm{TM}}$. We first wanted to evaluate the accuracy of the parameters measured in a bench model. We tested the system at different settings "prompting" various leak ranges, at different compliance and resistance levels, to reproduce situations observed in clinical practice. These tests confirmed the accuracy of this system in terms of leak detection and MV. The correlation 


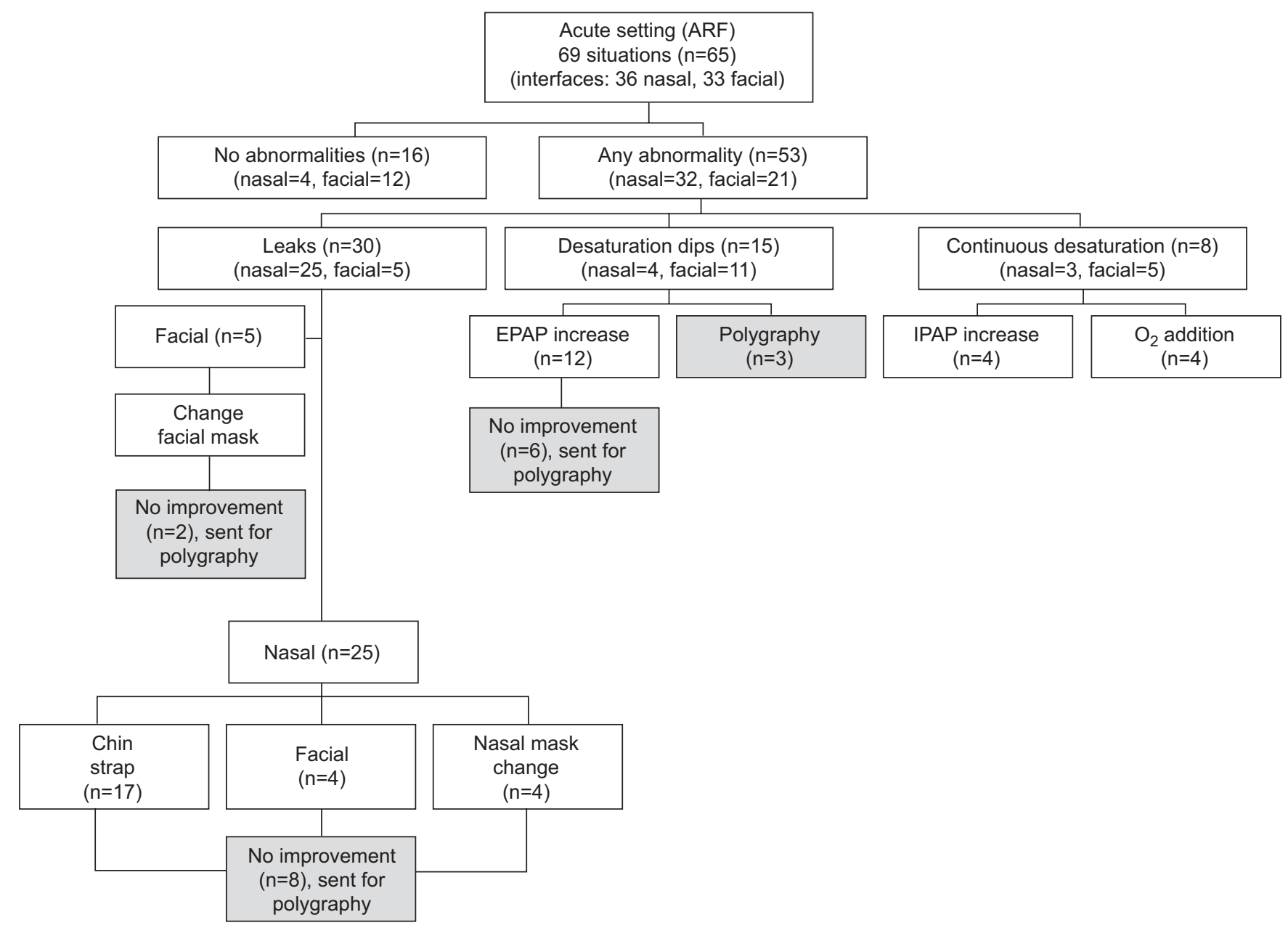

FIGURE 4. Monitoring results classified by clinical situation and subsequent therapeutic modifications in the acute setting group. ARF: acute respiratory failure; EPAP: expiratory positive airway pressure; IPAP: inspiratory positive airway pressure.

between the bench test and ResLink ${ }^{\mathrm{TM}}$ was less reliable with low leak levels, but, since such leak levels would not degrade the quality of ventilation they are probably not clinically relevant.

We have assessed the usefulness of the ResLink ${ }^{\mathrm{TM}}$ device in monitoring NIV in clinical practice. This approach is pertinent since, to date, only a limited number of studies have specifically addressed the question of NIV evaluation during the night. Moreover, the validity of several parameters estimated by NIV devices is questionable and must be validated by independent clinical and/or bench test studies [17].

One can estimate that by permitting evaluation of some "critical signals" (for instance arterial oxygen saturation, leaks and MV) this system could provide useful information about the global quality of ventilation. The occurrence of oxygen desaturations (both desaturation dips and continuous desaturation) is highly sensitive at detecting breathing abnormalities in NIV users. Moreover, unintentional leaks are probably the main phenomena that impair ventilatory effectiveness [17] and are extremely frequent in patients receiving NIV [18, 19]. Finally, whereas the main goal of ventilatory assistance is to ensure physiological MV, it allows us to estimate this parameter. Therefore, an analysis combining the three signals provided by this device may offer a global estimation of NIV quality. Using this procedure enabled us to observe abnormalities liable to change the efficacy of the NIV in $66 \%$ of cases. This is higher than reported in the literature $(5-60 \%)[20,21]$, perhaps because the efficacy criteria selected were very rigorous, but also because a more subtle methodology of analysis was used in order to rule out false negative results. We defined ventilation as ineffective when we observed one of the following abnormalities: leak, episodes of continuous desaturation or desaturation dips. Suboptimal ventilation was more common at the start of ventilation treatment; therefore, the number of traces and PG/PSG required, and consequently the number of modifications made, was higher in that period. The better ventilation performance observed in patients assessed at a later period may reflect greater clinical stability or a "training effect" [22], but may also reflect that many of these patients had undergone monitoring at the start of the NIV, making early intervention possible. The abnormalities were less common when an FM was used, but this difference was only significant in the acute phase. The better results with FM in the acute phase is found in clinical practice, given that in acute NIV FM are most commonly used, while for chronic NIV NM use predominates [4, 23]. Finally, 


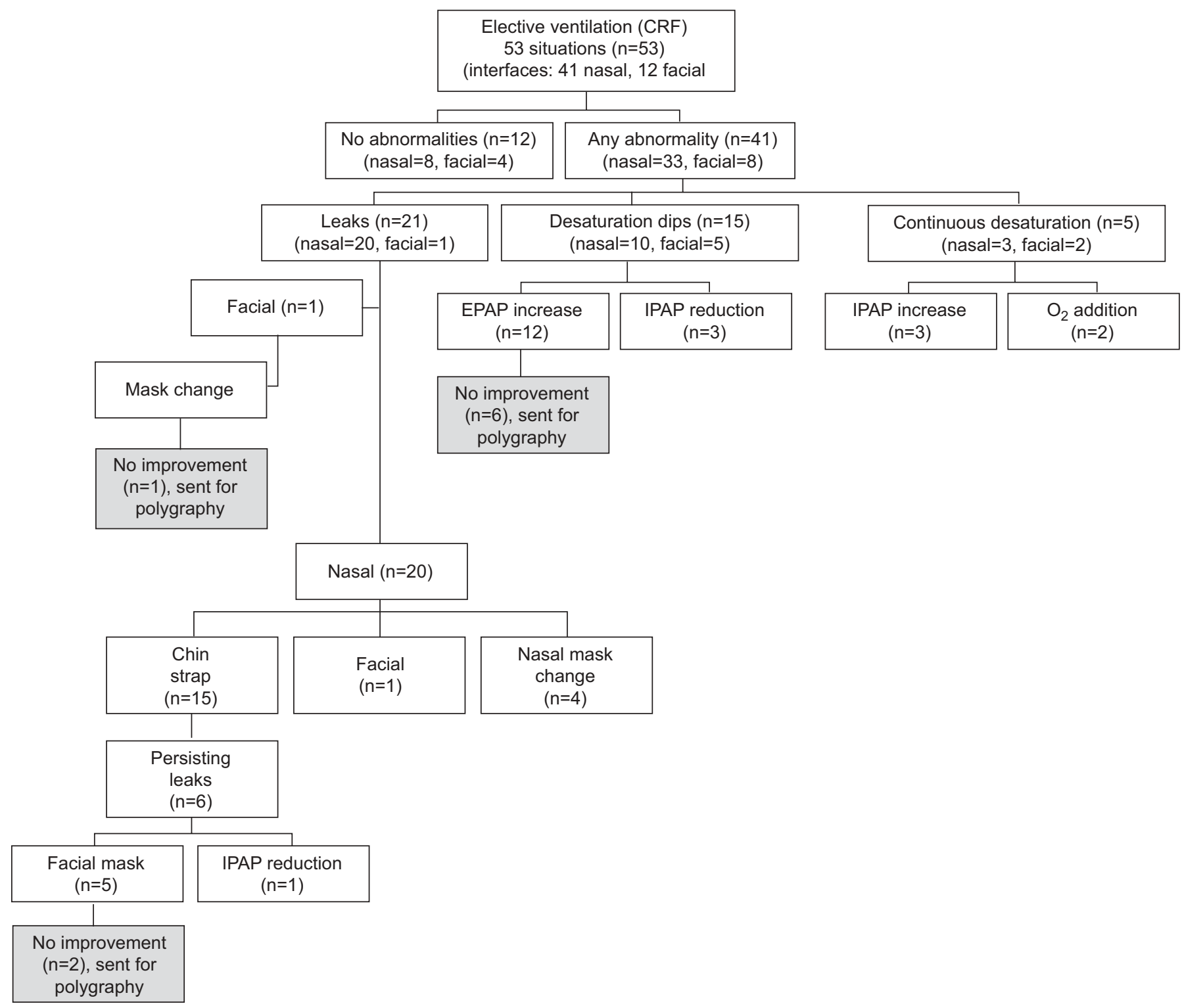

FIGURE 5. Monitoring results classified by clinical situation and subsequent therapeutic modifications in the elective ventilation group. CRF: chronic respiratory failure; EPAP: expiratory positive airway pressure; IPAP: inspiratory positive airway pressure.

the proportion of patients with suboptimal ventilation was unrelated to the type of underlying disease.

In the acute setting, greater hypercapnia at the start of the ventilation correlated with a greater probability of inefficacy of NIV. This can be explained by the need, in these patients, to modify the $\mathrm{Pa}_{\mathrm{a}} \mathrm{CO}_{2}$ to a greater extent, which could cause "resistance" to the ventilation, as has been described previously [24]. For stable patients, there was a significant correlation between the presence of abnormalities in ResLink $^{\mathrm{TM}}$ data and a reduced efficacy of NIV, particularly in terms of $\mathrm{Pa}_{1} \mathrm{O}_{2}, \mathrm{pH}$ and $\mathrm{HCO}_{3}{ }^{-}$. As well as $\mathrm{Pa}_{2}, \mathrm{CO}_{2}$, serum bicarbonate levels reflect the effectiveness of nocturnal ventilation $[25,26]$. Given that compliance in both groups (normal and abnormal) was similar, these differences in blood gases cannot be explained by a difference in the use of the ventilator. If one assumes that the primary objective of ventilation is to correct the ABG [2], these findings call attention to the importance of monitoring results as markers of ineffective ventilation.

Leak was the most commonly found abnormality as is expected in a non-hermetic system such as NIV [21, 26], and can compromise the efficacy of the method, reduce compliance and disturb sleep quality $[18,19,27]$. Generally, a leak of $<24 \mathrm{~L} \cdot \mathrm{min}^{-1}$ is considered clinically tolerable $[18,20,25$, 27]. Different portable ventilators allow leak to be estimated, but the performance of their algorithms is variable [26]. In addition, for most of these algorithms, intentional leaks are included in the leak estimations, which are variable and proportional to the level of pressure and different for each interface. The ResLink ${ }^{\mathrm{TM}}$ has the particular feature of taking into account the intentional leak and subtracting it, thereby estimating the "undesired" leak level. Solutions for reducing 


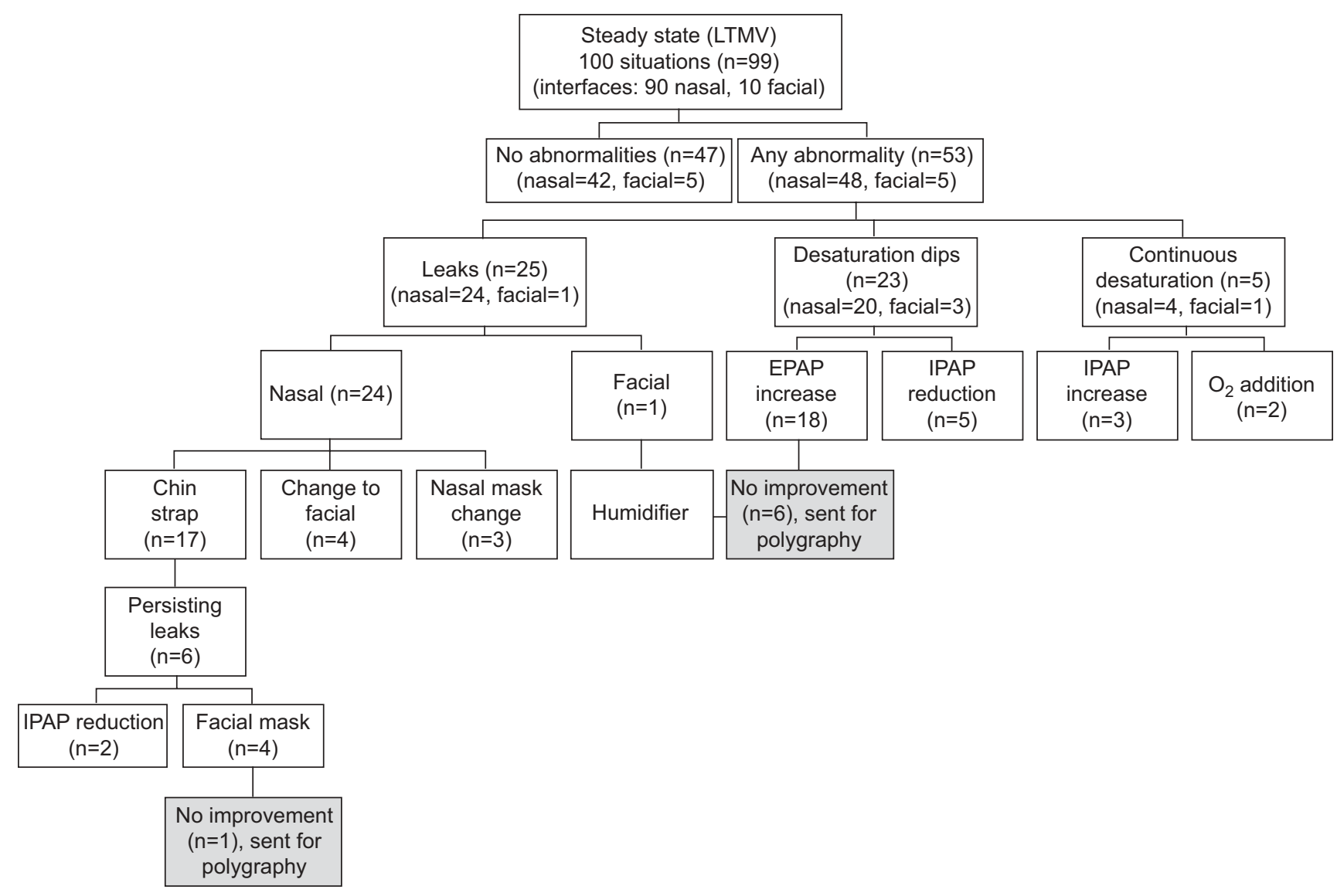

FIGURE 6. Monitoring results classified by clinical situation and subsequent therapeutic modifications in patients evaluated at a steady state. LTMV: long-term mechanical ventilation; EPAP: expiratory positive airway pressure; IPAP: inspiratory positive airway pressure.

leak include chin straps and using an FM or mouth interfaces [18]. Although the use of chin straps has been reported to reduce leak volume by $<50 \%$ [25], in our study and in other studies [28] this was effective in a large number of patients.

Desaturation dips reflect intermittent obstruction of the UA under NIV and are related to two mechanisms. The first corresponds to obstructive events at the oropharyngeal level because of UA collapse, as a result of insufficient EPAP. This mechanism may be present in patients with an unstable UA, such as patients with obstructive sleep apnoea [29, 30]. Another mechanism corresponds to episodes of intermittent obstruction at the glottal level reflecting cyclic glottal closure induced by hyperventilation, a type of "ventilation resistance" reflex [9, 31-33]. Interestingly, desaturation dips were more frequent when an FM was used, particularly in patients in an acute situation. There are several possible explanations for this. One is that greater modification of $\mathrm{Pa}_{\mathrm{a}} \mathrm{CO}_{2}$ as a result of more hermetic ventilation could promote the occurrence of glottal closure episodes [24]. Another is that the use of FM predominantly induces mouth breathing, which may promote significant narrowing of the retropalatal distance predisposing to oropharyngeal obstruction [34]. The application of positive pressure in the mouth could worsen this situation even further [34].

The fact that it is impossible to identify the underlying mechanism of these desaturation dips explains that this abnormality was the one that led most frequently to performing a
PG/PSG. In these situations, the purpose of PG/PSG was to identify the mechanism of the UA obstruction [21, 35]. If obstruction occurs at the oropharyngeal level it will be accompanied by progressively increased inspiratory activity, indicating a struggle against UA collapse. Conversely, if the mechanism is glottal closure it will be accompanied by reduced inspiratory effort, the result of an excessive level of ventilation promoting respiratory pauses $[31,36]$. In the case of oropharyngeal apnoea, the approach is to increase the level of EPAP to stabilise the UA. In the case of glottal apnoea, however, it is to reduce the MV [31].

The third pathological ResLink ${ }^{\mathrm{TM}}$ pattern was represented by regular desaturation episodes, whether or not accompanied by a simultaneous reduction of MV. Two mechanisms could explain this abnormality: 1) the inefficacy of the system to ensure adequate ventilation, which is generally accompanied by diurnal hypercapnia; and 2) a worsening of the ventilation perfusion imbalance, known as a cause of nocturnal hypoxaemia in patients with respiratory failure [29]. Monitoring transcutaneous carbon dioxide tension is a useful tool for the differential diagnosis between these mechanisms, although this assessment is under utilised [29]. In our bench study, the $\operatorname{ResLink}^{\mathrm{TM}}$ device gave a good estimate of MV and, thus, may be useful for differentiation between the mechanisms of regular desaturations, but this needs to be confirmed by other studies. 
TABLE 3 Monitoring results: classified by type of abnormality for each interface and effective therapeutic modifications

Subjects $^{\# \quad \text { Abnormalities detected/patients Effective therapeutic intervention }}{ }^{+}$

PG/PSG needed evaluated in each situation

\begin{tabular}{|c|c|c|}
\hline Nasal mask ${ }^{\S}$ & & \\
\hline Leak & $69(41.3)$ & ARF: $25 / 36(69.4)$ \\
\hline & & CRF: 20/41 (48.7) \\
\hline & & LTMV: 24/90 (26.6) \\
\hline Desaturation dips & $34(20.4)$ & ARF: $4 / 36(11.1)$ \\
\hline & & CRF: 10/41 (24.4) \\
\hline & & LTMV: 20/90 (22.2) \\
\hline Continuous desaturation & $10(5.9)$ & ARF: $3 / 36(8.33)$ \\
\hline & & CRF: $3 / 41$ (7.3) \\
\hline & & LTMV: $4 / 90(4.4)$ \\
\hline Facial mask ${ }^{f}$ & & \\
\hline Leak & $7(12.7)$ & ARF: $5 / 33(15.1)$ \\
\hline & & CRF: $1 / 12(8.3)$ \\
\hline & & LTMV: $1 / 10(10.0)$ \\
\hline Desaturation dips & 19 (34.5) & ARF: 11/33 (33.3) \\
\hline & & CRF: $5 / 12(41.7)$ \\
\hline & & LTMV: $3 / 10(30.0)$ \\
\hline Continuous desaturation & $8(14.5)$ & ARF: $5 / 33(15.1)$ \\
\hline & & CRF: 2/12 (16.7) \\
\hline & & LTMV: $1 / 10(10)$ \\
\hline
\end{tabular}

Data are presented as $n(\%), n / n$ or n/n (\%). PG: ventilatory polygraphy; PSG: full polysomnography; ARF: acute respiratory failure; CRF: chronic respiratory failure; LTMV long-term mechanical ventilation; IPAP: inspiratory positive airway pressure; EPAP: expiratory positive airway pressure. \#: percentages correspond to the proportion of patients with each abnormality/total of patients classified by interface; " : percentages correspond to the proportion of patients with each abnormality/total of patients in a given situation; ${ }^{+}$: percentages correspond to the proportion of patients improved by each therapeutic intervention/total number of patients as classed by abnormality: s. $n=167 ; f: n=55$

A number of criticisms may be made with regard to our study. Concerning the bench study, the tests were performed using a passive lung model, which may not accurately reproduce physiological conditions. The estimate of leak by the ResLink ${ }^{\mathrm{TM}}$ may be less accurate with assisted breathing, given that the velocity of the turbine (and accordingly the estimate of leak level) can vary in the presence of inspiratory effort.

TABLE 4 Comparison in terms of arterial blood gases between patients with normal and abnormal traces

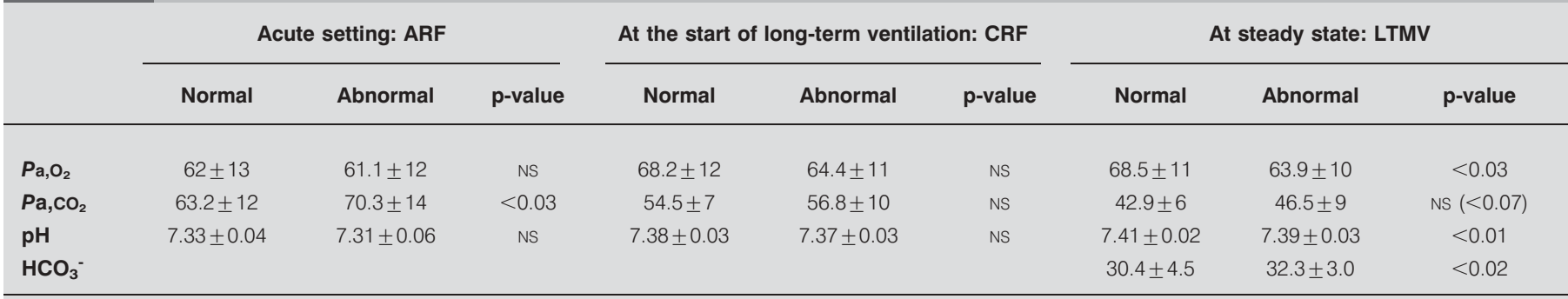

Data are presented as mean $\pm \mathrm{SD}$, unless otherwise stated. The values correspond to arterial blood gases performed before the start of the ventilation in the acute respiratory failure (ARF) and chronic respiratory failure (CRF) groups, and during the first hour in the morning following disconnection from the ventilator in the long-term mechanical ventilation (LTMV) group. As arterial carbon dioxide tension $\left(\mathrm{Pa}_{1} \mathrm{CO}_{2}\right)$ varies rapidly, lack of difference in terms of $\mathrm{Pa}, \mathrm{CO}_{2}$ between normal and abnormal traces in the LTMV group may be explained by the arterial blood gases sample timing. Note that the arterial oxygen tension $\left(\mathrm{Pa}, \mathrm{O}_{2}\right)$ difference between normal and abnormal traces in the LTMV group cannot be explained by a different prescription of oxygen ( 15 out of 53 patients in the abnormal group and nine out of 47 in the normal group; nonsignificant (NS)). 
Regarding the clinical study, first, the study includes patients with various pathologies and heterogeneous clinical situations and, additionally, the parameters defined as a threshold of normality are arbitrary. However, our objective was to propose a screening method that can be used in daily practice. Thus it was necessary to include a representative sample of practice and establish criteria that reflect the quality of ventilation and which have already been suggested as markers of NIV inefficacy [12, 25]. Secondly, our definition of ineffective ventilation was based only on the results of the traces without taking into account ABG or clinical response. Future research should assess the importance of combining the results of this monitoring with other variables. Thirdly, since ResLink ${ }^{\mathrm{TM}}$ provides only trend data and not raw data of ventilation, this system does not allow an analysis of patient-ventilator interaction to detect asynchrony. Nevertheless, it has been well established that, in patients receiving NIV, major leak is probably the most important contributor to these events [12], and our evaluation includes its detection. Finally, as with all oximeters, oxygen supplementation may affect the reliability of arterial oxygen saturation measured by this device.

In summary, monitoring by this system makes it possible, with accessible technology, to assess the quality of the ventilation and interpret the results easily, which facilitates its application in screening patients in a real-life situation. If the results prove to be less than expected, this system makes it possible to first clarify the pathophysiological mechanism responsible and, if changes are required, to subsequently check the results of these changes. The systematic use of this system enables NIV to be optimised, limiting the indication of PG/PSG to complex cases. The importance of including the results of this simplified monitoring with other assessment variables of ventilation quality should be the objective of future research.

\section{STATEMENT OF INTEREST}

None declared.

\section{ACKNOWLEDGEMENTS}

We would like to thank C. Duvivier (Unité de Physiopathologie Respiratoire, Université Poincaré, Nancy, France), D. Veale (ANTADIR, Paris, France), P. Leger (Laboratoire du sommeil, Service de Pneumologie, CHU Lyon Sud, Lyon, France) and S. Sortor-Leger (ResMed, France) for their kind and helpful collaboration and for correcting our English, and the technician team of Alize de Bourgogne (Dijon, France) for their excellent technical assistance.

\section{REFERENCES}

1 Fanfulla F, Delmastro M, Berardinelli A, et al. Effects of different ventilator settings on sleep and inspiratory effort in patients with neuromuscular disease. Am J Respir Crit Care Med 2005; 172: 619-624.

2 Clinical indications for noninvasive positive pressure ventilation in chronic respiratory failure due to restrictive lung disease, COPD, and nocturnal hypoventilation - a consensus conference report. Chest 1999; 116: 521-534.

3 Gonzalez MM, Parreira VF, Rodenstein DO. Non-invasive ventilation and sleep. Sleep Med Rev 2002; 6: 29-44.

4 Schonhofer B, Sortor-Leger S. Equipment needs for noninvasive mechanical ventilation. Eur Respir J 2002; 20: 1029-1036.

5 Bland JM, Altman DG. Statistical methods for assessing agreement between two methods of clinical measurement. Lancet 1986; 1 : 307-310.
6 Lloyd-Owen SJ, Donaldson GC, Ambrosino N, et al. Patterns of home mechanical ventilation use in Europe: results from the Eurovent survey. Eur Respir J 2005; 25: 1025-1031.

7 Jounieaux V, Parreira V, Delguste P, et al. Nasal mask pressure waveform and inspiratory muscle rest during nasal assisted ventilation. Am J Respir Crit Care Med 1997; 155: 2096-2101.

8 Parreira VF, Delguste P, Jounieaux V, et al. Glottic aperture and effective minute ventilation during nasal two-level positive pressure ventilation in spontaneous mode. Am J Respir Crit Care Med 1996; 154: 1857-1863.

9 Jounieaux V, Aubert G, Dury M, et al. Effects of nasal positivepressure hyperventilation on the glottis in normal awake subjects. J Appl Physiol 1995; 79: 176-185.

10 Parreira VF, Delguste P, Jounieaux V, et al. Effectiveness of controlled and spontaneous modes in nasal two-level positive pressure ventilation in awake and asleep normal subjects. Chest 1997; 112: 1267-1277.

11 French Pulmonary Society. [Non-invasive positive pressure ventilation for neuromuscular diseases. Practice guidelines]. Rev Mal Respir 2006; 23: 14S15-14S40.

12 Guo YF, Sforza E, Janssens JP. Respiratory patterns during sleep in obesity-hypoventilation patients treated with nocturnal pressure support: a preliminary report. Chest 2007; 131: 1090-1099.

13 Freeman ML, Hennessy JT, Cass OW, et al. Carbon dioxide retention and oxygen desaturation during gastrointestinal endoscopy. Gastroenterology 1993; 105: 331-339.

14 Kopka A, Wallace E, Reilly G, et al. Observational study of perioperative $\mathrm{PtcCO}_{2}$ and $\mathrm{SpO}_{2}$ in non-ventilated patients receiving epidural infusion or patient-controlled analgesia using a single earlobe monitor (TOSCA). Br J Anaesth 2007; 99: 567-571.

15 Jounieaux V, Rodenstein DO. [Home mechanical ventilation: indications and pathophysiological limitations]. Rev Mal Respir 2004; 21: 358-366.

16 Robert D, Argaud L. Non-invasive positive ventilation in the treatment of sleep-related breathing disorders. Sleep Medicine 2007; 8: 441-452.

17 Pépin J-L, Borel JC, Janssens JP, et al. Sleep and NIV: monitoring of the patient under home ventilation. In: Muir J-F, Ambrosino N, Simonds AK, eds. Noninvasive Ventilation. Eur Respir Mon 2008; 41: 350-366.

18 Teschler H, Stampa J, Ragette R, et al. Effect of mouth leak on effectiveness of nasal bilevel ventilatory assistance and sleep architecture. Eur Respir J 1999; 14: 1251-1257.

19 Meyer T, Pressman M, Benditt J, et al. Air leaking through the mouth during nasal ventilation: effect on sleep quality. Sleep 1997; 20: 561-569.

20 Heather S, Simmonds A, Ward S. Problem solving in acute NIPPV. In: Simmonds AK, ed. Non-Invasive Respiratory Support. London, Edward Arnold, 2001; pp. 146-159.

21 Rabec CA, Reybet-Degat O, Bonniaud $\mathrm{P}$, et al. Leak monitoring in noninvasive ventilation. Arch Bronconeumol 2004; 40: 508-517.

22 Achour L, Letellier C, Cuvelier A, et al. Asynchrony and cyclic variability in pressure support noninvasive ventilation. Comput Biol Med 2007; 37: 1308-1320.

23 Elliott MW. The interface: crucial for successful noninvasive ventilation. Eur Respir J 2004; 23: 7-8.

24 Parreira VF, Jounieaux V, Delguste P, et al. Determinants of effective ventilation during nasal intermittent positive pressure ventilation. Eur Respir J 1997; 10: 1975-1982.

25 Teschler $\mathrm{H}$. Monitoring of the home mechanical ventilated patient. In: Muir J-F, Ambrosino N, Simonds AK, eds. Noninvasive Ventilation. Eur Respir Mon 2001; 16: 274-280.

26 Gonzalez J, Macey J, Cracco C, et al. Initiation and management of home mechanical ventilation. Rev Mal Respir 2004; 21: 783-790. 
27 Bach J, Robert D, Leger $\mathrm{P}$, et al. Sleep fragmentation in kiphoscoliotic individuals with alveolar hypoventilation treated by NIPPV. Chest 1995; 107: 1552-1558.

28 Willson GN, Piper AJ, Norman M, et al. Nasal versus full face mask for noninvasive ventilation in chronic respiratory failure. Eur Respir J 2004; 23: 605-609.

29 Pepin JL, Chouri-Pontarollo N, Orliaguet O, et al. Alveolar hypoventilation during sleep and domiciliary assisted ventilation. Rev Mal Respir 2005; 22: 113-125.

30 Rabec C, Merati M, Baudouin N, et al. Management of obesity and respiratory insufficiency. The value of dual-level pressure nasal ventilation. Rev Mal Respir 1998; 15: 269-278.

31 Jounieaux V, Aubert G, Dury M, et al. Effects of nasal positivepressure hyperventilation on the glottis in normal sleeping subjects. J Appl Physiol 1995; 79: 186-193.
32 Parreira VF, Jounieaux V, Aubert G, et al. Nasal two-level positivepressure ventilation in normal subjects. Effects of the glottis and ventilation. Am J Respir Crit Care Med 1996; 153: 1616-1623.

33 Delguste P, Aubert-Tulkens G, Rodenstein DO. Upper airway obstruction during nasal intermittent positive-pressure hyperventilation in sleep. Lancet 1991; 338: 1295-1297.

34 Lee $\mathrm{SH}$, Choi JH, Shin C, et al. How does open-mouth breathing influence upper airway anatomy? Laryngoscope 2007; 117: 1102-1106.

35 Fanfulla F, Taurino AE, Lupo NDA, et al. Effect of sleep on patient/ ventilator asynchrony in patients undergoing chronic non-invasive mechanical ventilation. Respir Med 2007; 101: 1702-1707.

36 Nakayama H, Smith CA, Rodman JR, et al. Effect of ventilatory drive on carbon dioxide sensitivity below eupnea during sleep. Am J Respir Crit Care Med 2002; 165: 1251-1260. 